\title{
Reproductive Health Practices of Female Garment Workers
}

\author{
Article by Mita Rahman ${ }^{1}$, Shafiur Rahman ${ }^{2}$, Ummul Khair Alam ${ }^{3}$, Irin Hossain ${ }^{4}$ \\ ${ }^{1,2,3}$ National Institute of Preventive and Social Medicine, Mohakhali, Dhaka \\ Email: irin.hossain@gmail.com
}

\begin{abstract}
A cross sectional descriptive study was carried out among the garments workers in two garments factory to assess the reproductive health practices of female garment workers with structured questionnaire by face to face interview. A total of two hundred female garment workers were selected purposively in this area who were married within 18-45 years of age. The proportion of women seeking abortion was 75\%. Among 28 respondents who were pregnant, highest proportion of them (89.3\%) were under regular ANC in pregnancy. More than one third (10.7\%) of the respondent were not under regular ANC. Among the 28 respondents half of the respondents (21.43\%) did not take Tetanus vaccination and half $(78.57 \%)$ took tetanus vaccination. This study reflected different dimension in their reproductive life, for improved their better standard. Large scale studies needed.
\end{abstract}

Keywords: Reproductive health practice, garment workers.

\section{Introduction}

About 34 million adolescents (10-19 years old) constitute 21\% of total population of Bangladesh [1]. Adolescents experience rapid social, physical and emotional changes [2]. More over reproductive life, nutrition, drug, early marriage, divorce, sexually transmitted disease play in important role in this time. The fertility rate among the 15-19 years old age group is one of the highest rates in the world. The percentage of married adolescent aged 15-19 is 11.4 and the fertility rate of this age group is 113 per 1,000 married women [3]. Teen pregnancy and motherhood is a major social and health concern. About $31 \%$ of female garments worker in Bangladesh have begun childbearing; about one in four teenagers has given birth and another 6\% are pregnant with their first child. As expected, the proportion of women age 15-19, who have begun childbearing rises rapidly with age, from $9 \%$ among women age 15 to 58 percent among women age 19. The information on Adolescent Reproductive Health (ARH) knowledge and behavior is extremely limited. Overall adolescent reproductive health issues are un-addressed for both married and unmarried females and males. Information about sexual behavior is not easy to obtain, partly because of a long-held assumption that young people do not engage in sex before marriage in Bangladesh's conservative culture. The limited information available indicates that conservative may not be protecting either gender from sexual experimentation with potentially negative effects on RH. In most cultures, boys are more likely to experiment sexually than girls, usually because the consequences are less severe. This appears to be true in Bangladesh as well, though there are sharp urban and rural differences.

Readymade garment sector has been playing an important role in enhancing Bangladesh economy. Women represent 85 percent of the total 24 million employees in readymade garment industry. Bangladesh is a society that has traditionally been characterized by very early marriage and child bearing when this is a period of physiological, emotional and intellectual development. Maternal mortality among mothers aged 15-19 is also very high as compared to among mothers in the 20-24 years age group [4]. Study in Turkey reported that approximately 90 percent of adolescent pregnancies are unplanned and a great amount unplanned adolescent pregnancies are unintended. They are not conscious about receiving antenatal and postnatal care. For this reason they have suffered various reproductive health related problems such as severe anaemia, nutritional deficiency, abortion, maternal and infant mortality, premature and low birth weight baby and even death. Mothers are at a risk of having anaemia in pregnancy, which is considered to be mainly responsible for the prevailing high maternal mortality and high incidence of low birth weight deliveries in India. Many adverse outcomes have been associated with teenage pregnancy including premature delivery, small 
for gestational age infants, low birth weight infants, increase neonatal mortality, anaemia and pregnancy induced hypertension [5]. Different reports suggested that adolescent are associate with increase incident of medical and obstetrical complications including anaemia, pregnancy-induced hypertension and prematurity. The pregnancy-related maternal and fetal complications in most cases were observed in a higher proportion when compared with those found in other studies in developing countries.

\section{Methods}

\section{Study design and sample}

This study was conducted to assess the reproductive health practices of female garment workers according to the following methodologies:

This study was conducted at two garments, Meherun Apparels Ltd Malibag, Dhaka. From the workers the sample was taken by convenient sampling. Among the female workers, those who were married and age between 18-45 years, willing to participate in the interview were interviewed at the factory total 200 women were interviewed. A semi structured questionnaire was used as research instrument. After adequate correction and thorough checking, the questionnaire was divided into part a. contained the questions related to the socioeconomic status, part $b$. contained the questions related to their reproductive health, part c. reproductive health practice questions to assess reproductive health practices of female garment workers. Data were collected by face to face interview, by asking them questions as per the written questionnaire at the factory. The study populations were interviewed one after another without disturbing their routine works. The interview was taken by the researcher herself at the site of the study.

\section{Analysis}

Collected data were analyzed after thorough checking, cleaning, editing and compiling by using the SPSS (Statistical package for social science, version 24 for windows) software and scientific calculator. Continuous variables were recorded into categorical variable by creating groups. The data were presented in different Tables, charts. The data were presented in different tables in order to the variables. Frequency tables according to the variables. Cross tables to see the reproductive health practice according to the socio-demographic variables. Chi-square test was done to see the relationship between reproductive health practice and some selected variables. The test statistics was used to analyze the data is descriptive statistics and inferential statistic according to the demand of the study with 95\% confidence interval. Level of significance was set at 0.05 . Qualitative data were analyzed on the basis of themes.

\section{Result}

This was a cross sectional study, conducted in garment factory with the main objective of the study was to assess the reproductive health practice among the female garment worker. A total of 200 patients were interviewed.

\section{Socio-demographic status of female workers}

Table 1 shows distribution of the respondents by age group. The minimum age was 18 years and the maximum age was 47 years. The mean age was $27.63( \pm 7.01)$ years. About one third $(33.5 \%)$ of the respondents were within the age group of 18-23 years, one third (32\%) was within 24-29 years, about one fifth (18.5\%) was within 30-35 years. Most 183 (91.5\%) of the respondents were Muslim, one twelfth $12(6 \%)$ were Hindu and rest of were Buddhists (1.5\%) and Christians (1\%) respectively.

Almost half $(49.5 \%)$ of the respondents were educated up to primary and one fourth $(24 \%)$ of the respondents were educated up to degree and $1 / 5^{\text {th }}(20 \%)$ of the respondents were illiterate. Out of the total 200 respondents minimum family members are 2 person and maximum family members are 6 persons. Mean family member is 4 persons $(\mathrm{SD} \pm 0.83)$. 
Table 1. Socio-demographic characteristics of the respondents $n=200$

\begin{tabular}{|l|l|l|}
\hline Characteristics & Frequency & Percent \% \\
\hline Age (Years) & 67 & 33.5 \\
\hline 18-23years & 64 & 32.0 \\
\hline 24-29years & 37 & 18.5 \\
\hline 30-35 years & 23 & 11.5 \\
\hline 36-41 years & 9 & 4.5 \\
\hline 42-47 years & \multicolumn{2}{|l|}{} \\
\hline Mean=27.63,SD =7.01 & 91.5 \\
\hline Religion & 183 & 6 \\
\hline Muslim & 12 & 2.5 \\
\hline Hinduism & 5 & 20.0 \\
\hline Others & 40 & 49.5 \\
\hline Respondent's education level & 6.0 \\
\hline Illiterate & 99 & .5 \\
\hline Primary & 12 & 24.0 \\
\hline Secondary & 1 & 48 \\
\hline Higher secondary & & \\
\hline Degree &
\end{tabular}

\section{Reproductive characteristics of the respondent $\mathbf{n}=\mathbf{2 0 0}$}

Table shows that out of 200 participants $94(47 \%)$ got married before 18 years that is early marriage was $47 \%$. Out of the total 200 respondents one third $66(33.0 \%)$ had 1 child and less than one third $63(31.5 \%)$ had 2 children and about one tenth $23(11.5 \%)$ had more than two children. Minimum number of children is 1 and maximum number of children is 4 . Average number of children is 2 ( $\mathrm{SD} \pm 0.96)$. Out of the total 200 respondents most of them $172(86 \%)$ were not pregnant and 28 (14\%) were pregnant.

Table 2. Reproductive characteristics of the respondent $n=200$

\begin{tabular}{|l|l|l|}
\hline Characteristics & Frequency & Percent \% \\
\hline \multicolumn{2}{|l|}{ Early Marriage (Years) } & 47.0 \\
\hline Less than 18 years & 94 & 53.0 \\
\hline 18 years and above & 106 & 24.0 \\
\hline 2. Number of living children & 33.0 \\
\hline No child & 48 & 31.5 \\
\hline One child & 66 & 11.5 \\
\hline Two child & 63 & 0.96 \\
\hline More than two & 23 & 86 \\
\hline Minimum=1, Maximum=4, Mean=2, SD $=4$ \\
\hline 3. Pregnancy status & 172 \\
\hline No
\end{tabular}




\begin{tabular}{|l|l|l|}
\hline Yes & 28 & 14 \\
\hline
\end{tabular}

\section{Distribution of the respondents by history of unplanned or unwanted pregnancy $n=152$}

Out of the total 152 respondents who had children, majority (70\%) of them had no history of unplanned or unwanted pregnancy and less than one third (30\%) had history of unplanned or unwanted pregnancy.

Table 3. Distribution of the respondents by history of unplanned or unwanted pregnancy

\begin{tabular}{|c|c|c|c|}
\hline $\begin{array}{l}\text { History of unplanned or } \\
\text { unwanted pregnancy }\end{array}$ & $\begin{array}{l}\text { History of unplanned or } \\
\text { unwanted pregnancy }\end{array}$ & Frequency & Percentage \\
\hline No & \multirow[t]{3}{*}{152} & 106 & 70 \\
\hline Yes & & 46 & 30 \\
\hline Total & & 152 & 100.0 \\
\hline
\end{tabular}

Distribution of the respondents by current pregnancy unplanned or unwanted $\mathbf{n}=\mathbf{2 8}$

Out of the total 28 respondents who were pregnant most of them $(71.4 \%)$ had history of planned pregnancy and more than one fifth $(28.6 \%)$ had unplanned or unwanted pregnancy.

Table 4. Distribution of the respondents by current pregnancy unplanned or unwanted

\begin{tabular}{|l|l|l|}
\hline $\begin{array}{l}\text { Present pregnancy planned } \\
\text { or not }\end{array}$ & Frequency & Percentage \\
\hline Planned & 20 & 71.4 \\
\hline Not planned & 8 & 28.6 \\
\hline Total & 28 & 100 \\
\hline
\end{tabular}

\section{Distribution of the respondents by history of $M R$ and number of MR $\mathbf{n}=\mathbf{2 0 0}$}

Out of the total 200 respondents three fourth $150(75 \%)$ of the respondents had history of MR and one fourth $50(25 \%)$ had no history of miscarriage or MR. Out of the total 150 respondents who had history of MR majority $105(70 \%)$ had once history of MR, one fourth $38(25 \%)$ had history for two times and only less than one tenth 7 (4.6\%) had history for more than two times.

Table 5. Distribution of the respondents by history of MR and number of MR

\begin{tabular}{|l|l|l|}
\hline History of MR & Frequency & Percentage \\
\hline History of MR & 150 & 75 \\
\hline No History of MR & 50 & 25 \\
\hline Number of MR & \multicolumn{2}{|l|}{} \\
\hline 1 & 105 & 70 \\
\hline 2 times & 38 & 25.4 \\
\hline$>2$ times & 7 & 4.6 \\
\hline Total & 150 & 100.0 \\
\hline
\end{tabular}

Distribution of the respondents by consultation about gap between children with husband $n=$ 152

Out of the total 152 respondents who had one child, two child or more, most of them $114(75 \%)$ talked about gap between two children and one forth 38 (25\%) did not consult with their husbands. 
Table 6. Distribution of the respondents by consultation about gap between children with husband

\begin{tabular}{|l|l|l|}
\hline $\begin{array}{l}\text { Consultation about gap between } \\
\text { children with husband }\end{array}$ & Frequency & Percentage \\
\hline No & 38 & 25 \\
\hline Yes & 114 & 75 \\
\hline Total & 152 & 100.0 \\
\hline
\end{tabular}

Distribution of the respondents by taking ANC in pregnancy, place of taking ANC and caregiver of $\mathrm{ANC}$ in previous pregnancy $\mathrm{n}=\mathbf{2 8}$

Out of the total 28 respondents, most 25 (89.3\%) had history of regular ANC in pregnancy and 3 $(10.7 \%)$ were irregular in taking ANC in pregnancy. Out of the total 27 respondents, majority 12 (40.74\%) had taken ANC in upazila health complex, 6 (22.22\%) in private doctor and $9(33.33 \%)$ in other places. Out of the total 88 respondents, most of the respondents $20(71.43 \%)$ was visited by dai in ANC of previous pregnancy, about one tenth $3(10.71 \%)$ and $5(17.86 \%)$ were visited by MBBS and paramedics respectively.

Table 7. Distribution of the respondents by taking ANC in pregnancy, place of taking ANC and caregiver of ANC in previous pregnancy

\begin{tabular}{|l|l|l|}
\hline Taking ANC in pregnancy & Frequency & Percentage \\
\hline No & 1 & 3.57 \\
\hline Irregular & 3 & 10.7 \\
\hline Regular & 25 & 89.3 \\
\hline Place of taking ANC & 12 & 44.44 \\
\hline Upazila Health Complex & 6 & 22.22 \\
\hline Private Doctor & 9 & 33.33 \\
\hline Others & 9 & 17.86 \\
\hline caregiver of ANC in previous pregnancy \\
\hline M.B.B.S & 5 & 10.71 \\
\hline Paramedics & 3 & 71.43 \\
\hline Dai & 20 & 100 \\
\hline Total & 28 & \\
\hline
\end{tabular}

\section{Distribution of the current pregnancy by tetanus vaccination $\mathbf{n}=\mathbf{2 8}$}

Out of the total 28 respondents, most of the respondents who were pregnant $22(78.57 \%)$ took tetanus vaccination and one fifth $6(21.43 \%)$ did not took tetanus vaccination.

Table 8. Distribution of the current pregnancy by tetanus vaccination

\begin{tabular}{|l|l|l|}
\hline $\begin{array}{l}\text { Tetanus vaccination } \\
\text { in current pregnancy }\end{array}$ & Frequency & Percentage \\
\hline No & 6 & 21.43 \\
\hline Yes & 22 & 78.57 \\
\hline Total & 28 & 100.0 \\
\hline
\end{tabular}

\section{Distribution of the respondents by full term delivery and type of delivery $n=152$}

Out of the total 152 respondents who had children, most of them 120 (78.95\%) had history of full term delivery and more than one fifth $32(21.05 \%)$ did not history of full term delivery. Out of the total 152 respondents who had children, most of them 130 (85.53\%) had normal delivery as mode of delivery and $22(14.47 \%)$ had caesarian section. 
DOI: $10.21522 /$ TIJPH.2013.06.02.Art023

ISSN: $2520-3134$

Table 9. Distribution of the respondents by full term delivery and type of delivery

\begin{tabular}{|l|l|l|}
\hline Full term delivery & Frequency & Percentage \\
\hline No & 32 & 21.05 \\
\hline Yes & 120 & 78.95 \\
\hline Type of delivery \\
\hline Caesarian section & 22 & 14.47 \\
\hline Normal delivery & 130 & 85.53 \\
\hline Total & 152 & 100.00 \\
\hline
\end{tabular}

\section{Discussion}

The study was carried out to describe the Reproductive Health Practices of Female Garment Workers in Selected Garment Factory. The study was done to assess the reproductive practices of female garment workers and to determine the socio-demographic characteristics of reproductive health practices.

The minimum age was 18 years and the maximum age was 47 years. The mean age was 27.63 $( \pm 7.01)$ years. About one third $(33.5 \%)$ of the respondents were within the age group of 18-23 years, one third (32\%) was within 24-29 years, about one fifth (18.5\%) was within 30-35 years. Almost half $(49.5 \%)$ of the respondents were educated up to primary and one fourth $(24 \%)$ of the respondents were educated up to degree and 1/5th (20\%) of the respondents were illiterate. Most 183(91.5\%) of the respondents were Muslim, one twelfth $12(6 \%)$ were Hindu and rest of were Buddhists (1.5\%) and Christians (1\%) respectively. Out of the total 200 respondents minimum family members are 2 person and maximum family members are 6 persons. Mean family member was 4 persons ( $\mathrm{SD} \pm 0.83)$. Out of 200 participants $94(47 \%)$ got married before 18 years that is early marriage was $47 \%$. Out of the total 200 respondents one third $66(33.0 \%)$ had 1 child and less than one third $63(31.5 \%)$ had 2 children and about one tenth $23(11.5 \%)$ had more than two children. Minimum number of children is 1 and maximum number of children is 4 . Average number of children is $2(\mathrm{SD} \pm 0.96)$. Out of the total 200 respondents most of them i.e. $172(86 \%)$ were not pregnant and $28(14 \%)$ were pregnant. Out of the total 152 respondents who had one child, two child or more, most of them 114 (75\%) talked about gap between two children and one forth $38(25 \%)$ did not consult with their husbands.

Out of the total 27 respondents, majority $12(40.74 \%)$ had taken ANC in upazila health complex, 6 (22.22\%) in private doctor and $9(33.33 \%)$ in other places. Out of the total 28 respondents, majority $16(57.14 \%)$ had history of taking ANC in previous pregnancy and $12(1.56 \%)$ did not take ANC in previous pregnancy. Out of the total 28 respondents, majority $16(57.14 \%)$ had history of taking ANC in previous pregnancy and $12(1.56 \%)$ did not take ANC in previous pregnancy. Out of the total 28 respondents, more than half $16(57.1 \%)$ had visited ANC two times in previous pregnancy, $8(28.6 \%)$ visited o Out of the total 88 respondents, most of the respondents20 $(71.43 \%)$ was visited by dai in ANC of previous pregnancy, about one tenth $3(10.71 \%)$ and $5(17.86 \%)$ were visited by MBBS and paramedics respectively. Out of the total 28 respondents, most of the respondents who were pregnant $22(78.57 \%)$ took tetanus vaccination and one fifth $6(21.43 \%)$ did not took tetanus vaccination. Out of the total 152 respondents who had children, most of them 120 (78.95\%) had history of full term delivery and more than one fifth $32(21.05 \%)$ did not history of full term delivery. Most of them 130 $(85.53 \%)$ had normal delivery as mode of delivery and $22(14.47 \%)$ had caesarian section. Out of the total 200 respondents, most of them 139 (69.5\%) did not use clean materials and less than one third 61 (30.5\%) used clean materials during menstruation. Out of the total 200 respondents, most of the respondents $88(44.0 \%)$ did not face any problem, $84(42 \%)$ had lower abdominal pain, one tenth 21 (10.5\%) developed weakness and a few 7 (3.5\%) developed nausea and vomiting during menstruation. most of them $176(88 \%)$ had not enough toilet facilities in their job places and only more than one tenth $24(12 \%)$ had enough toilet facilities.

\section{Conclusion}

Early marriage and childbearing among girls is often associated with a wide range of negative social and health consequences for young mothers and their infants, and contributes to rapid population growth. Regarding early marriage it was found that less than half female respondents were 
below 18 years and among that respondents majority having children, few of them were mother before their first anniversary. Among the respondents, less than one third had history of unplanned or unwanted pregnancy and three fourth had history of miscarriage or abortion. About antenatal checkup in pregnancy, among the 27 respondents who were presently pregnant higher portion of the respondents were taking regular ANC in pregnancy and few respondents were irregularly taking ANC. Majority of the respondents who were currently pregnant received Tetanus vaccination.

\section{Acknowledgement}

I am extremely grateful to my respected teacher Assistant Professor Dr. Md. Shafiur Rahman my supervisor for his continuous support and scholarly guidance despite his busy schedules. I express my sincere gratitude to Prof. Manzurul Haque Khan, PhD, Program in charge MPH (OEH). I also express special thanks to Dr. Shaheen Bin Abdul Hai and Dr. Irin Hossain, Lecturer, Department of Occupational and Environmental Health for their valuable advices, constructive suggestions and support to me regarding the whole task of the thesis.

I express my profound thanks to the Managing Director of Meherun Apparels, Malibag Chowdhury Para, Dhaka. At the same time I would like to extend my sincere thanks to all the respondents of this study for their kind participation.

\section{References}

[1].Afrin S, Rahman MR, Jahan AA, Zaman UKS, Rahman N, Rahman S. Reproductive health problems among the adolescent girls. Bangladesh Medical Journal 2010; 39 (2): 22-25.

[2].Akhter HH, Korim F, MEEK, Rahman MH. A study to identify the risk factors affecting nutritional status of adolescent girls in Bangladesh. BIRPERHT, Dhaka, Bangladesh 2000: II-X.

[3].Bangladesh Bureau of Statistics. Statistical pocket book. Dhaka 1999; 384-404.

[4].BDHS, 2014

[5].BRAC Annual Education Report, (2006).

[6].Dutta DC. Text book of Gynecology including contraception, Chapter-3: 2nd edition. New Central Book Agency P. Ltd., Calcutta, India. 1994: 480-483.

[7].Gupta. An assessment of reproductive health related problems of adolescent girls, India, AULAST 2004; 71(9): 797-801.

[8].Hassen F. An intervention program regarding adolescent health. NIPSOM, Bangladesh 1999: 65-70.

[9].Khan MR, Huq N. A Study on menstruation: Belief and practices of adolescents' girls. Dhaka: BRAC, 1991: 1415 .

[10]. Majumder PP, Begum A. Policy Research Report on Gender and Development. Working paper series no. 12.Dhaka, Bangladesh, 2000: 8.

[11]. Nahar Q, Tunon C, Houvras I, Gazi R, Reza M, Huq NL, et al. Reproductive Health needs of Adolescents in Bangladesh : A Study Report. Dhaka, ORP: ICDDR, B. Bangladesh 1999: 17-36.

[12]. Parveen T, Ali HM, Haque AM. Reproductive health related complaints of adolescent school girls of Dhaka city, JOPSOM 2003; 22(2):1-5.

[13]. Pathak, K.B \& Ram, F: Adolescent motherhood: Problems and consequences. The Journal of Family Welfare, (1993), March 15, vol 39(1), pp 17-23.

[14]. Sharma A; Verma k; Khatri S. kannan A on Pregnancy in adolescent: a study of risks and outcome in Eastern Nepal, (2001); vol 38; pp 1405-1409.

[15]. WHO Adolescent health report on Bangladesh (2016). 